\title{
Review
}

\section{Advances in Epidemiological Studies of Herpes Zoster}

Yuan Liu

Department of Dermatovenereology, Tianjin Medical University General Hospital, Tianjin China

\section{Keywords}

Herpes zoster; incidence; risk factor;

epidemiology

\section{Correspondence}

Yuan Liu,

E-mail: yliutjmu@126.com

DOI: 10.1515/ii-2017-0119

\begin{abstract}
Herpes zoster (HZ) is a varicella zoster virus (VZV) that attacks locality of nerves and skin, resulting in formation of clusters of blisters on the skin connected unilateral facial nerve and accompanying apparent nerve pain. Incidence ranges from 3.2 to 4.2 per 1000 populations per year in the United States. Influence factors of $\mathrm{HZ}$ include age, infection history with VZV, vaccination history of varicella vaccine, reduced immunocompetence, and other diseases. Current domestic studies on $\mathrm{HZ}$ mainly focus on clinical reports of case treatment. This study reviews advances in foreign epidemiological studies of HZ.
\end{abstract}

Herpes zoster $(\mathrm{HZ})$ is a skin infection caused by reactivation of varicella-zoster virus (VZV), which is latent in sensory ganglia. Typical features of this infection cause herpes along sensory nerves in corresponding segments and accompanying severe neuropathic pain, seriously affecting quality of life. Several countries, such as the United States, Britain, and Australia, studied epidemiological characteristics of $\mathrm{HZ}$. Current domestic studies on $\mathrm{HZ}$ mainly focus on clinical reports of case treatment. Epidemiological studies on $\mathrm{HZ}$ are few, and they cannot provide basis for formulating strategies regarding $\mathrm{HZ}$ immunity. This study introduces advances in foreign epidemiological studies of $\mathrm{HZ}$.

\section{Pathogenesis and infection of $\mathrm{HZ}$}

VZV belongs to herpes virus subfamily. Clinical manifestation of initial infection is varicella, and susceptible age is those of children. VZV is transmitted to epithelial tissues after mass propagation and infects junction cells between dermis and epidermis, leading to characteristic blister damage. Simultaneously, the end of sensory axon is located at the junction between the dermis and epidermis at the bottom of skin blisters. After recovery from blisters, VZV proceeds to axons and becomes latent in nerve cells of sensory ganglia. Latency and reactivation of VZV are closely related to specific immunity. After initial infection with $\mathrm{VZV}$, the body produces specific immunities against VZV; these immune reactions include VZV-specific antibodies and $\mathrm{T}$ cell-mediated immunity, which play important roles in maintenance of VZV latency and $\mathrm{HZ}$ prevention. When immune level decreases, VZV is activated, and $\mathrm{HZ}$ infection occurs.

$\mathrm{HZ}$ patients afflicted with rash to incrustation are infectious ${ }^{[1-3]}$. Breakage of $\mathrm{HZ}$ contains high concentrations of VZV, which can form aerosols and spread ${ }^{[4]}$. Susceptible population can be infected and acquire varicella. $\mathrm{HZ}$ is less infectious than varicella because of differences in their transmission routes. A study showed that in the same family, varicella was acquired by $15.5 \%$ of persons in contact with $\mathrm{HZ}$ patients and $71.5 \%$ of individuals in contact with varicella patients ${ }^{[5]}$. Therefore, $\mathrm{HZ}$ patients should be isolated until herpes scab. Close contacts should undergo medical observation, and varicella susceptible population should be inoculated with varicella vaccine to prevent development of related diseases.

\section{Epidemiology of $\mathbf{H Z}$}

Incidence level 
No country in the world classified $\mathrm{HZ}$ as notifiable infectious disease. Some countries conducted studies on incidence level of HZ. In the United States, incidence ranges from 3.2 to 4.2 per 1000 populations per year. With increase in age, incidence of $\mathrm{HZ}$ increases, and incidence rate of people over 60 reaches 10 per 1000 populations per year ${ }^{[6-8]}$. HZ also exhibits recurrence. A Minnesota study followed up for six years showed that recurrence rate of $\mathrm{HZ}$ reaches 14 per 1000 populations per year ${ }^{[9]}$. Studies in the US and UK indicated that hospitalization rate of $\mathrm{HZ}$ totals $2.1-16.1$ per 1,000,000 populations per year ${ }^{[10,11]}$. Hospitalization rate of $\mathrm{HZ}$ increases with age. A US study showed that hospitalization rate of $\mathrm{HZ}$ among people aged at and over 85 years old was 75 times higher than that of people under $30^{[12]}$. A study in Australia showed $1 \%$ mortality rate in hospitalized patients primarily diagnosed with HZ. Mortality rate of patients over 65 years old is 10 times higher than that of younger people ${ }^{[13]}$. Immunosuppression is one of the major risk factors leading to hospitalization and death in patients with HZ. Up to $30 \%$ of hospitalized patients with $\mathrm{HZ}$ and $52 \%$ of deaths are accompanied by one or more immune system damages, such as malignant tumor, leukemia, and HIV infection.

\section{Risk factors}

Age Age is the most important risk factor of HZ. Studies of different designs and in different areas all showed that incidence of $\mathrm{HZ}$ increases with age. Incidence of children under 10 reaches 0.74 per 1000 populations per year. Incidence increases gradually in the ten-year-old age group. From 50-60 years old, this increase becomes significant; $\mathrm{HZ}$ incidence in people aged 80 to 90 totals 10 per 1000 populations per year ${ }^{[14]}$. Specific immune level of organism decreases with age. After initial infection of varicella, antibody levels decrease with time; this phenomenon may be due to increased incidence of $\mathrm{HZ}$ with age ${ }^{[15]}$. Age is also the main risk factor for neuralgia in patients with $\mathrm{HZ}$. A number of studies showed that risk of $\mathrm{HZ}$ accompanied by neuropathic pain increases with age, especially for people over the age of 50; among these individuals, $80 \%-85 \%$ experience neuralgia ${ }^{[16]}$. Risk for at least two months of neuropathic pain is 27.4 times of that of population under 50 [17].

Gender No agreed conclusion can explain the relationship between gender and incidence of $\mathrm{HZ}$. In a prospective cohort study in New Zealand, risk of HZ in women was $38 \%$ higher than that in men after adjustment for age and other risk factors (95\% confidence interval was $1.22-1.56)^{[18]}$. Other studies also indicated that incidence of $\mathrm{HZ}$ in women was higher after standardization of age ${ }^{[19]}$. However, parts of studies did not show statistical differences in incidence of HZ between genders ${ }^{[20,21]}$.

Seasonal and geographical factors Most studies did not found seasonal incidence of $\mathrm{HZ}^{[22]}$. Several studies showed high incidence during summer, when ultraviolet rays possibly stimulated HZ in exposed skin ${ }^{[23,24]}$. No studies showed that incidence of $\mathrm{HZ}$ is related to regional latitude and distribution of rural areas ${ }^{[25]}$.

VZV infection history Reactivation of latent VZV causes $\mathrm{HZ}$. Therefore, previous VZV infection serves as necessary condition for occurrence of HZ ${ }^{[26]}$. Serum antibody levels showed that $99.5 \%$ of people over 40 were previously infected by VZV. Though most people did not remember suffering from varicella, VZV infection rate reminded elders of risk of $\mathrm{HZ}^{[27]}$.

VZV contact history Individuals exposed to varicella can reduce risk of $\mathrm{HZ}$ by increasing levels of VZV-specific antibodies. British monitoring data analysis showed that incidence of varicella among children under five was inversely proportional to that in adults aged 15-44 years old ${ }^{[28]}$. Multivariate analysis showed that compared with those who were not exposed to varicella, exposure to varicella for three to four times decreases risk of $\mathrm{HZ}$ by $74 \%$ times, and exposure of less than three times also reduces such incidence ${ }^{[29]}$. A cohort study of UK sentinel surveillance showed that incidence of varicella increased in adults with access to varicella and living with children, whereas incidence of $\mathrm{HZ}$ decreased by $25 \%$. This protection can last for 20 years (95\% confidence interval was $7-14$ years) ${ }^{[30]}$. Other evidence support the opposite view that exposure to varicella does not reduce risk of $\mathrm{HZ}$. Women may be more exposed to children with varicella, whereas studies showed much higher risk of $\mathrm{HZ}$ in women than in men.

History of varicella vaccine immunization In varicella vaccine inoculator, attenuated vaccine strains can lead to $\mathrm{VZV}$ recessive infection, virus reactivation, and $\mathrm{HZ}$ infection [31]. In clinical manifestations, distinguishing $\mathrm{HZ}$ caused by vaccine strain and wild strain is not possible. Varicella 
vaccine inoculator may already be infected with the virus or was infected with the virus due to immune failure after vaccination. Therefore, estimating risk of $\mathrm{HZ}$ caused by vaccine strains is improbable. Compared with individuals who were previously infected with varicella, risk of $\mathrm{HZ}$ reduces by $65 \%$ in immunodeficient children with history of one dose of varicella vaccine, and risk of $\mathrm{HZ}$ also reduces in children with normal immune function ${ }^{[32]}$.

Reduced immunocompetence Unlike other infectious diseases that can be prevented by vaccines, direct cause of $\mathrm{HZ}$ infection is not exposure to pathogens. However, latent $\mathrm{VZV}$ is activated after specific biological changes. Immune dysfunction is a risk factor for $\mathrm{HZ}$ and severe complications. Incidence of $\mathrm{HZ}$ in patients with malignant tumors reaches approximately $5 \%$, which is higher than that of normal population of the same age ${ }^{[33]}$. Risk of the disease is determined by nature of tumor and treatment ${ }^{[34]}$. Incidence of $\mathrm{HZ}$ of patient $\mathrm{He}$ Jinjie reached as high as $27.3 \%{ }^{[35]}$. After hematopoietic stem cell transplantation, $\mathrm{HZ}$ becomes much common; incidence rate totals $13 \%-55 \%$ in the first year after operation ${ }^{[36]}$. After organ transplantation, incidence of $\mathrm{HZ}$ reaches 5\%-17\%; the majority of $\mathrm{HZ}$ occurs one year after operation ${ }^{[37]}$. Incidence of $\mathrm{HZ}$ in HIV-infected adults totals $29.4-51.5$ per 1000 populations per year; this value is $12-17$ times higher than that of HIV-negative patients [38-40]. Incidence of $\mathrm{HZ}$ in $\mathrm{HIV}$-infected children is much higher compared with HIV-negative children; in children at inhibitory stage, incidence reaches 467 per 1000 populations per year $^{[41]}$.

Other diseases Risk of HZ increases in patients with inflammatory diseases. Morbidity of $\mathrm{HZ}$ in patients with systemic lupus erythematosus reaches $15-91$ per 1000 populations per year ${ }^{[42,43]}$. Incidence of $\mathrm{HZ}$ in patients with arthritis is approximately 10 per 1000 populations per year ${ }^{[44]}$. Morbidity of HZ in patients with Wegner' s granulomatosis totals 45 per 1000 populations per year ${ }^{[45]}$. Crohn's disease and ulcerative colitis are both related to incidence of $\mathrm{HZ}$, and risks amount to 1.6 and 1.2, respectively ${ }^{[46]}$. Risk of $\mathrm{HZ}$ in patients with inflammatory disease also increases. Two studies showed association of diabetes with $\mathrm{HZ}{ }^{[47]}$. However, other studies failed to verify their correlation ${ }^{[48]}$. One study reported an increased risk of $\mathrm{HZ}$ in patients with multiple sclerosis ${ }^{[49]}$.
Other risk factors Trauma or surgery can activate latent VZV in the dorsal ganglion, thus increasing risk of $\mathrm{HZ}^{[50}$ ${ }^{-52]}$. A case-control study showed that incidence of such case is close to that in the control group without herpes skin trauma. However, in patients with $\mathrm{HZ}$, the proportion of trauma within a few months before onset of skin lesions was significantly higher than that in the control group; risk reached 12.1 (95\% confidence interval was $1.5-$ 97.6) ${ }^{[53]}$. Psychological stress plays a certain role in $\mathrm{HZ}$ pathogenesis. A case-control study showed that incidence of $\mathrm{HZ}$ was associated with stress in life within six months ${ }^{[54]}$. Mechanisms of these risk factors causing incidence of $\mathrm{HZ}$ require further elucidation. However, immunity factors play important roles in $\mathrm{HZ}$ occurrence. Genetic predisposition of $\mathrm{HZ}$ was also reported. Polymorphism of interleukin-10 gene is related to $\mathrm{HZ}$ pathogenesis ${ }^{[55,56]}$.

$\mathrm{HZ}$, especially post herpetic neuralgia, seriously affects patients' body, psychology, daily life, and work. Onset risk is associated with age, VZV infection history, reduced immunocompetence, and other diseases. HZ vaccine was listed abroad in 2006 and was recommended for use in elderly over 60 after estimation of $\mathrm{HZ}$ burden in the United States. Formulation of vaccine immunization strategies in different countries depends on epidemiological characteristics of national diseases, efficacy and safety of vaccine, and economic burdens. Few studies focused on pathogenesis, disease burden, and risk factors of $\mathrm{HZ}$ in China. Thus, basic data are insufficient when $\mathrm{HZ}$ vaccine becomes listed in our country in the future. In this sense, providing reliable evidence for development of $\mathrm{HZ}$ vaccine strategies poses a challenge. Therefore, our country should investigate or establish a $\mathrm{HZ}$ monitoring system, understand epidemiological characteristics and risk factors of $\mathrm{HZ}$, provide scientific basis for prevention and control of herpes zoster, and conduct public health strategies for vaccine use.

\section{Declarations}

\section{Acknowledgements}

No.

\section{Competing interests}

The author declares that he has no competing interest.

\section{Authors' contributions}


Y Liu made the literature analysis and wrote, discussed and revised the manuscript of this review.

\section{References}

1 Wreghitt TG, Whipp J, Redpath C, et al. An analysis of infection control of varicella-zoster virus infections in Addenbrooke's Hospital Cambridge over a 5-year period, 1987-92. Epidemiol Infect, 1996, 117 (1):165-171.

2 Brunell PA, Argaw T. Chickenpox attributable to a vaccine virus contracted from a vaccinee with zoster. Pediatrics, 2000,106(2): E28.

3 Lopez AS, Burnett-Hartman A, Nambiar R, et al. Transmission of a newly characterized strain of varicella-zoster virus from a patient with herpes zoster in a long-term-care facility, West Virginia, 2004. J Infect Dis, 2008, 197 (5):646-653.

4 Sawyer MH, Chamberlin CJ, Wu YN, et al. Detection of varicella-zoster virus DNA in air samples from hospital rooms. J Infect Dis, 1994, 169 (1):91-94

5 Seward JF, Zhang JX, Maupin TJ, et al. Contagiousness of varicella in vaccinated cases: a household contact study. JAMA, 2004,292 (6):704-708.

6 Jumaan Aishao, Yu O, Jackson LA, et al. Incidence of herpes zoster, before and after varicella-vaccination-associated decreases in the incidence of varicella,1992-2002. J Infect Dis,2005, 191 (12):2002-2007.

7 Donahue JG, Choo PW, Manson JE, et al. The incidence of herpes zoster. Arch Intern Med, 1995, 155 (15):1605-1609.

8 Mullooly JP, Riedlinger K, Chun C, et al. Incidence of herpes zoster, 1997-2002. Epidemiol Infect, 2005, 133 (2): 245-253.

9 Yawn BP, Saddier P, Wollan PC, et al. A population-based study of the incidence and complication rates of herpes zoster before zoster vaccine introduction. Mayo Clin Proc, 2007, 82 (11): 1341-1349.

10 Coplan P, Black S, Rojas C, et al. Incidence and hospitalization rates of varicella and herpes zoster before varicella vaccine introduction: a baseline assessment of the shifting epidemiology of varicella disease. Pediatr Infect Dis J, 2001, 20 (7):641-645.

11 Brisson M, Edmunds WJ. Epidemiology of Varicella-Zoster virus in England and Wales. J Med Virol,2003,70 (Suppl 1): S9-14.

12 Macintyre CR, Chu CP, Burgess MA. Use of hospitalization and pharmaceutical prescribing data to compare the prevaccination burden of varicella and herpes zoster in Australia. Epidemiol Infect, 2003,131 (1):675-682.

13 Chant KG, Sullivan EA, Burgess MA, et al. Varicella-zoster virus infection in Australia. Aust N Z J Public Health, 1998, 22(4): 413-418.

14 Oxman MN, Levin MJ, Johnson GR, et al. A vaccine to prevent herpes zoster and postherpetic neuralgia in older adults. N Engl J Med, 2005,352 (22):2271-2284

15 Levin MJ, Smith JG, Kaufhold RM, et al. Decline in varicella-zoster virus $(\mathrm{VZV})$-specific cell-mediated immunity with increasing age and boosting with a high-dose VZV vaccine. J Infect Dis,2003,188 (9):1336-1344.

16 Schmader K. Postherpetic neuralgia in immunocompetent elderly People. Vaccine, 1998,16 (18):1768-1770.

17 Choo PW, Galil K, Donahue JG, et al. Risk factors for postherpetic neuralgia. Arch Intern Med, 1997,157 (11):1217-1224.

18 Opstelten W, Van Essen GA, Schellevis F, et al. Gender as an Independent risk factor for herpes zoster: a population-based prospective study. Ann Epidemiol, 2006,16 (9):692-695.

19 Fleming DM, Cross KW, Cobb WA, et al. Gender difference in the incidence of shingles. Epidemiol Infect, 2004,132 (1):1-5.

20 Jung BF, Johnson RW, Griffin DR, et al. Risk factors for postherpetic neuralgia in patients with herpes zoster. Neurology, 2004, 62 (9):1545-1551.

21 Scott FT, Leedham-Green ME, Barrett-Muir WY, et al. A study of shingles and the development of postherpetic neuralgia in East London.J Med Virol, 2003,70 (Suppl 1): S24-S30.

22 Brisson M, Edmunds WJ, Law B, et al. Epidemiology of varicella zoster virus infection in Canada and the United Kingdom. Epidemiol Infect, 2001,127 (2):305-314.

23 Zak-Prelich M, Borkowski JL, Alexander F, et al. The role of solar ultraviolet irradiation in zoster. Epidemiol Infect, 2002, 129(3):593-597.

24 Gallerani M, Manfredini R. Seasonal variation in herpes zoster infection. Br J Dermatol,2000,142 (3):588-589.

25 Thomas SL, Hall AJ. What does epidemiology tell us about risk factors for herpes zoster?. Lancet Infect Dis, 2004,4 (1):26-33.

26 Kelley PW, Petruccelli BP, Stehr-Green P, et al. The susceptibility of young adult Americans to vaccine-preventable infections. A National serosurvey of US Army recruits. JAMA, 1991, 266(19):2724-2729.

27 Kilgore PE, Kruszon-Moran D, Seward JF, et al. Varicella in americans from NHANES III:implications for control through routine immunization. J Med Virol,2003,70 (Suppl 1): S111-S118.

28 Garnett GP, Grenfell BT. The epidemiology of varicella-zoster virus infections: the influence of varicella on the prevalence of herpes zoster. Epidemiol Infect, 1992, 108 (3):513-528.

29 Thomas SL, Wheeler JG, Hall AJ. Contacts with varicella or with children and protection against herpes zoster in adults:a case-control study. Lancet, 2002,360 (9334):678-682.

30 Brisson M, Gay NJ, Edmunds WJ, et al. Exposure to varicella boosts immunity to herpes-zoster: implications for mass vaccination against chickenpox. accine, 2002, 20 (19/20):2500-2507.

31 Takayama N, Takayama M, Takita J. Herpes zoster in healthy children immunized with varicella vaccine. Pediatr Infect Dis J,2000,19 (2):169-170.

32 Gershon AA. Live-attenuated varicella vaccine. Infect Dis Clin North Am, 2001, 15 (1):65-81,viii.

33 Rusthoven JJ, Ahlgren P, Elhakim T, et al. Varicella-zoster infection in 
adult Cancer patients. A population study. Arch Intern Med, 1988, 148 (7):1561-1566.

34 Dunst J, Steil B, Furch S, et al. Herpes zoster in breast Cancer patients after radiotherapy. Strahlenther Onkol, 2000, 176(11):513-516.

35 Rusthoven JJ. The risk of varicella-zoster infections in different patient populations:a critical review. Transfus Med Rev,1994,8(2):96-116.

36 Arvin AM. Varicella-Zoster virus: pathogenesis, immunity, and clinical management in hematopoietic cell transplant recipients. Biol Blood Marrow Transplant, 2000,6 (3):219-230.

Gourishankar S, Mcdermid JC, Jhangri GS, et al. Herpes zoster infection following solid organ transplantation: incidence, risk factors and outcomes in the current immunosuppressive era. Am J Transplant, 2004, 4 (1):108-115.

38 Mcnulty A, Li Y, Radtke U, et al. Herpes zoster and the stage and prognosis of HIV-1 infection. Genitourin Med,1997,73 (6): 467-470.

39 Glesby MJ, Hoover DR, Tan Tianren, et al. Herpes zoster in women with and at risk for HIV: data from the Women's Interagency HIV Study. J Acquir Immune Defic Syndr, 2004, 37 (5):1604-1609.

40 Gebo KA, Kalyani R, Moore RD, et al. The incidence of, risk factors for, and sequelae of herpes zoster among HIV patients in the highly active antiretroviral therapy era. J Acquir Immune Defic Syndr,2005,40 (2):169-174

41 Gershon AA, Mervish N, Larussa P, et al. Varicella-zoster virus infection in children with underlying human immunodeficiency virus infection. J Infect Dis, 1997, 176 (6):1496-1500.

42 Pope JE, Krizova A, Ouimet JM, et al. Close association of herpes zoster reactivation and systemic lupus erythematosus (SLE) diagnosis: casecontrol study of patients with SLE or noninflammatory nusculoskeletal disorders. J Rheumatol, 2004, 31(2):274- 279.

43 Kang TY, Lee HS, Kim TH, et al. Clinical and genetic risk factors of herpes zoster in patients with systemic lupus erythematosus. Rheumatol Int, 2005, 25 (2):97-102.

44 Smitten AL, Choi HK, Hochberg MC, et al. The risk of herpes zoster in patients with rheumatoid arthritis in the United States and the United Kingdom. Arthritis Rheum, 2007, 57 (8):1431-1438.

45 Wung PK, Holbrook JT, Hoffman GS, et al. Herpes zoster in immunocompromised patients: incidence, timing, and risk factors. Am J Med,2005,118 (12):1416.

46 Gupta G, Lautenbach E, Lewis JD. Incidence and risk factors for herpes zoster among patients with inflammatory bowel disease. Clin Gastroenterol Hepatol, 2006, 4 (12):1483-1490.

47 Heymann AD, Chodick G, Karpati T, et al. Diabetes as a risk factor for herpes zoster infection: results of a population-based study in Israe. Infection, 2008, 36 (3):226-230.

48 Arndt V, Vine MF, Weigle K. Environmental chemical exposures and risk of herpes zoster. Environ Health Perspect, 1999, 107 (10):835-841.

49 Ross RT, Cheang M, Landry G, et al. Herpes zoster and multiple sclerosis. Can J Neurol Sci, 1999, 26 (1):29-32.

50 Massad MG, Navarro RA, Rubeiz H, et al. Acute postoperative shingles after thoracic sympathectomy for hyperhidrosis. Ann Thorac Surg, 2004, 78 (6):2159-2161.

51 Gilden DH, Katz RI. Surgical induction of zoster in a contralateral homologous dermatomal distribution. Arch Neurol, 2003, 60(4):616-617.

52 Andrews TR, Perdikis G, Shack RB. Herpes zoster as a rare complication of liposuction. Plast Reconstr Surg, 2004, 113 (6): 1838-1840.

53 Thomas SL, Wheeler JG, Hall AJ. Case-control study of the effect of mechanical trauma on the risk of herpes zoster. BMJ, 2004, 328(7437):439.

54 Schmader K, Studenski S, Macmillan J, et al. Are stressful Life events risk factors for herpes zoster?. J Am Geriatr Soc, 1990, 38 (11):1188-1194.

55 Cho JW, Shin DH, Lee KS. Polymorphism of the IL-10 gene is associated with susceptibility to herpes zoster in Korea. J Dermatol Sci, 2007, 45 (3):213-215

56 Haanpaa M, Nurmikko T, Hurme M. Polymorphism of the IL-10 gene is associated with susceptibility to herpes zoste. Scand J Infect Dis, 2002, $34(2): 112-114$. 